\title{
A política de contratualização dos hospitais de ensino: o que mudou na prática?
}

\author{
The contracting policy of teaching hospitals: \\ what did actually change?
}

Arthur Chioro (https://orcid.org/0000-0001-7184-2342) ${ }^{1}$

Rosemarie Andreazza (https://orcid.org/0000-0002-3332-2183) ${ }^{1}$

Lumena Almeida Castro Furtado (https://orcid.org/0000-0001-7897-9739) ${ }^{1}$

Eliane Cardoso de Araújo (https://orcid.org/0000-0001-5123-0314) ${ }^{1}$

Mariana Arantes Nasser (https://orcid.org/0000-0001-8409-7265) ${ }^{1}$

Luiz Carlos de Oliveira Cecílio (https://orcid.org/0000-0002-9207-4781) ${ }^{1}$

${ }^{1}$ Departamento de Medicina Preventiva, Escola Paulista de Medicina, Universidade Federal de São Paulo. R. Botucatu 740, 451, Vila Clementino. 04023-062 São Paulo SP Brasil. arthur. chioro@unifesp.br

\begin{abstract}
The Teaching Hospital Restructuring Program was introduced as a strategy to fight the crisis in this sector. It brings to new funding, management and relationship standards between teaching hospitals and health system. This study presents the results obtained from a multiple case study involving four teaching hospitals whose contracts were executed in 2004. In 2010, a number of 32 interviews were conducted with both hospital and SUS managers, in addition to managers connected with the Federal Government Departments involved in the contracting system. By using elements from the micropolicy of health organizations as theoretical reference, the database was revisited with the goal of analyzing possible changes derived from such governmental policy applied in the daily life of teaching hospitals, in an attempt to explain the position taken by the diverse institutional actors as well as the main role played by the managers and the difficulties encountered in its introduction. Despite the improvements in the financial situation, the changes observed in teaching hospitals were not significant. An analysis of the contracting policy leads to an understanding of how a consistent and idealized project can reproduce the usual conservative behavior found in public management.
\end{abstract}

Key words Health policy, Health management, Hospital management, Teaching hospitals
Resumo O Programa de Reestruturação dos Hospitais de Ensino (HE) foi implantado como uma das estratégias para enfrentar a crise do setor. Pretendia introduzir novos modos de financiamento, de gestão e articulação destes hospitais com a rede de saúde. O artigo apresenta resultados de estudo qualitativo, de caso múltiplo, envolvendo quatro HE contratualizados em 2004. Foram entrevistados, em 2010, 32 dirigentes hospitalares, gestores do Sistema Único de Saúde (SUS) e dos ministérios envolvidos. Utilizando como referencial teórico elementos da micropolítica das organizações de saúde, revisitou-se o banco de dados como objetivo analisar as mudanças decorrentes dessa politica governamental no cotidiano dos $H E$, procurando caracterizar o posicionamento $e$ protagonismo dos diferentes atores institucionais e as dificuldades na sua implementação. A despeito da melhoria das condições financeiras, as mudanças observadas nos HE foram restritas. Analisar a política de contratualização permite compreender como um projeto consistente e idealizado pode reproduzir o comportamento conservador que caracteriza a gestão pública.

Palavras-chave Politica de saúde, Gestão em saúde, Administração hospitalar, Hospitais de ensino 


\section{Introdução}

O governo federal concebeu, em 2003, um Programa de Reestruturação dos Hospitais de Ensino (HE) que contemplava transferência significativa de recursos financeiros aos gestores do SUS com o objetivo de promover profundas mudanças nos HE a partir da relação contratual e do financiamento público destes estabelecimentos. Foi formulado num contexto de crise (crônica) dos HE e produzido a partir de consensos que deram viabilidade à política, inclusive com a captação de novos recursos financeiros disputados intensamente entre outras prioridades governamentais ${ }^{1}$.

Inserido na política que pretendia a reforma do sistema hospitalar brasileiro, procurou restabelecer compromissos dos gestores do SUS e dos HE a partir de quatro dimensões: assistência e a inserção dos HE no SUS; gestão dos HE; pesquisa, ensino e formação de trabalhadores da saúde; avaliação e incorporação tecnológica².

Em 2004, a Portaria no 1.000/MS/MEC instituiu o processo de certificação dos HE, primeiro passo para adesão ao Programa de Reestruturação. O seguinte foi o estabelecimento de portarias específicas normatizando a contratualização dos hospitais universitários vinculados ao MEC e os demais $\mathrm{HE}^{3}$, que definiram contratualização como:

o meio pelo qual as partes, o representante legal do HE e o gestor local do SUS, estabeleceriam metas quantitativas e qualitativas do processo de atenção à saúde, de ensino e pesquisa e de gestão hospitalar que deveriam ser acompanhadas e atestadas pelo Conselho Gestor da Instituição ou pela Comissão Permanente de Acompanhamento de Contratos ${ }^{4}$.

Com a contratualização pretendia-se indicar obrigações e responsabilidades de cada um dos atores envolvidos; implantar metas quanti e qualitativas; definir critérios e instrumentos de monitoramento e avaliação de resultados; desenvolver atividades de educação permanente (EP) para a rede; fortalecer os mecanismos de participação social; redefinir a inserção dos HE na rede de saúde; e, promover a regulação do sistema de saúde como um todo. Almejava-se, ainda, induzir políticas prioritárias do SUS, como a Política Nacional de Humanização (PNH) ${ }^{5}$ e a participação dos HE nos sistemas de urgência ${ }^{6}$. Da mesma forma, esperava-se a adoção do planejamento estratégico plurianual e participativo e de sistemas de informações para a tomada de decisões a partir de um sistema de avaliação de desempenho de gestão.

O contrato de gestão, com metas fixadas em um plano operativo anual, deveria indicar custos e eficiência/efetividade dos serviços prestados. O HE ficaria sujeito à regulação, controle e avaliação de resultados, estando prevista revisão das cláusulas do contrato ou mesmo suspensão (temporária ou definitiva), se necessário.

O modelo de financiamento foi modificado. Até então, o pagamento era baseado apenas na produção de serviços. O novo modelo previa orçamento global misto: parte por orçamentação e outra por mecanismos indutores da eficiência/ eficácia. Apenas procedimentos de alta complexidade continuariam sendo pagos por produção. $\mathrm{O}$ valor orçado, transferido regular e mensalmente aos HE, incluiu a média complexidade e outros recursos (FIDEPS e INTEGRASUS), acrescidos do valor correspondente ao novo incentivo à contratualização. Após cumprir as metas pactuadas, o HE poderia usar recursos excedentes segundo suas necessidades.

Entre 2004 a 2008, foram certificados 151 hospitais e 119 celebraram a contratualização com o seu gestor, gerando um impacto anual equivalente a $\mathrm{R} \$ 345$ milhões.

Esta normatização foi complementada com a publicação da Portaria no 3.390/2013, que instituiu a Política Nacional de Atenção Hospitalar (PNHOSP), posteriormente substituída pela Portaria de Consolidação GM/MS no 2, de 2017, que reafirmam o hospital como parte da rede de cuidados e que seu desenho assistencial responda às necessidades do SUS 7 .

O presente artigo toma como objeto de investigação a política precursora das normativas implementadas ao longo desta década para a contratualização de hospitais e, em particular, para os hospitais de ensino.

Tem por objetivo avaliar uma política governamental - a contratualização dos HE -, dando ênfase às mudanças que foram produzidas em suas dimensões estratégicas. Procura caracterizar o posicionamento dos diferentes atores institucionais e o protagonismo dos gestores locais do SUS na sua implementação, assim como as dificuldades na implantação dos instrumentos de contratualização. Busca, assim, ampliar a capacidade de compreensão dos dilemas atuais para a gestão e contratualização dos HE, aportando elementos teóricos-conceituais para o debate atual. 


\section{Metodologia}

O estudo foi conduzido por meio de uma investigação qualitativa, do tipo estudo de caso múltiplo, em quatro hospitais contratualizados como $\mathrm{HE}$, escolhidos aleatoriamente. Localizados em três UF distintas: dois pertenciam a universidades federais, um era público estadual, gerido por uma Organização Social (OS) vinculada à universidade estadual, e outro a uma instituição filantrópica.

Foram realizadas, conforme disposto no Quadro 1, 28 entrevistas com gestores responsáveis pela implementação e acompanhamento da política e com membros da direção superior dos HE. Outras quatro foram realizadas em Brasília, com dirigentes do Ministério da Saúde (MS), do Ministério do Planejamento, Orçamento e Gestão (MPOG) e do Ministério da Educação (MEC), que atuavam diretamente na coordenação da política. As perguntas da entrevista foram elaboradas a partir das diretrizes e instrumentos legaisque compõem a política de contratualização dos HEs, tomando-se por base seus quatro eixos prioritários (gestão, assistência, ensino e avaliação tecnológica).

A pesquisa de campo foi realizada em 2010 e as transcrições das entrevistas compõem o material empírico primário revisitado pelos pesquisadores em busca de elementos teóricos que permitissem compreender a política de contratualização dos $\mathrm{HE}$ ainda vigente. A sistematização e análise do material coletado foi realizado a partir dos quatro eixos temáticos da contratualização dos HE.

Buscou-se na micropolítica, na dinâmica concreta das complexas organizações tipificadas como HE, compreender como foi implantada, na prática, apolítica imaginada e produzida em âmbito federal, com forte poder de indução. Política que se insere no mesmo contexto de outras, construídas a partir de princípios ético-políticos comprometidos com o SUS, pautada por cuidadosa discussão com atores estratégicos, mas que ao serem operacionalizadas por atores concretos e em contextos complexos, assumem outros contornos, são apreendidas e reelaboradas no âmbito local de uma maneira peculiare, em processo, assumem novas intencionalidades e conformações ${ }^{1}$. Afinal, os atores portam valores, projetos, interesses e disputam sentidos para o trabalho em saúde, um campomarcado por disputas, acordos e composições, coalizões e afetos, atravessado e constituído por relações de poder; que na micropolítica há o "racional" e o "irracional", vetores de mudança, mas também de muita conservação ${ }^{8}$.

$\mathrm{O}$ estudo, realizado com financiamento da Fundação de Amparo à Pesquisa de São Paulo (FAPESP), foi aprovado pela Comissão de Ética da Unifesp/HSP.

Quadro 1. Gestores entrevistados para realização da pesquisa, por campo e cargo/função.

\begin{tabular}{|l|l|}
\hline \multicolumn{1}{|c|}{ Campo } & \multicolumn{1}{c|}{ Cargo/Função } \\
\hline $\mathrm{HE}_{1}$ & $\begin{array}{l}\text { Superintendente; Diretor administrativo; Gerente de desenvolvimento e informação; Coordenador } \\
\text { Médico dos Ambulatórios; Diretora de Enfermagem }\end{array}$ \\
\hline $\mathrm{HE}_{2}$ & $\begin{array}{l}\text { Diretor-Superintendente; Diretora de Assistência; Diretor Administrativo; Gerente de } \\
\text { Enfermagem; Coordenadora do Centro de Ensino e Pesquisa, do Núcleo de Saúde Pública e da } \\
\text { Comissão de Qualidade }\end{array}$ \\
\hline $\mathrm{HE}_{1}$ e HE & Gestor responsável pela política de contratualização dos HEs no âmbito da SES \\
\hline $\mathrm{HE}_{3}$ & $\begin{array}{l}\text { Diretor-Geral e Administrativo; Diretor Técnico e Clínico; Diretor Acadêmico; Supervisora de } \\
\text { Enfermagem; Coordenador da Gerência de Regulação de Serviços de Saúde da SMS; Médico } \\
\text { responsável pelo Núcleo de Relacionamento com os Prestadores da SMS }\end{array}$ \\
\hline $\mathrm{HE}_{4}$ & $\begin{array}{l}\text { Diretor Geral; Diretor Administrativo; Diretor Técnico; Diretora de Enfermagem; Diretor Clínico; } \\
\text { Gerente de Finanças; Gerente do OS; Assessor do Reitor; Ex-Reitor da Universidade; Secretário } \\
\text { Municipal de Saúde }\end{array}$ \\
\hline $\begin{array}{l}\text { Ministério } \\
\text { da Saúde }\end{array}$ & $\begin{array}{l}\text { Coord. Geral de Atenção Hospitalar do Dep. de Atenção Especializada da SAS /MS; Consultor } \\
\text { Técnico da Coordenação Geral Hospitalar /DAE/SAS/MS; Coordenador de Ações Estratégicas do } \\
\text { Dep. de Gestão do Ensino e do Trabalho da Secretaria de Gestão e Educação do Trabalho em Saúde }\end{array}$ \\
\hline MEC & $\begin{array}{l}\text { Coord. Geral de Residências em Saúde, da Diretoria de Hospitais Universitários e Residências em } \\
\text { Saúde }\end{array}$ \\
\hline MPOG & $\begin{array}{l}\text { Gerente de Projeto da Secretaria de Gestão do MPOG } \\
\text { Fonte: Elaborado pelos autores. }\end{array}$ \\
\hline
\end{tabular}




\section{Resultados e discussão}

\section{Atenção à saúde}

Uma das diretrizes da política para os $\mathrm{HE}$ era a desmobilização das ações de atenção básica ainda prestadas no HE, constituindo novos cenários de ensino-aprendizagem na rede básica9 ${ }^{9} \mathrm{O}$ impacto dessa estratégia foi inexpressivo. Os $\mathrm{HE}$ continuaram ofertando tais cuidados, sob alegação de garantir clientela para o ensino de $\mathrm{AB}$ aos alunos e residentes, mesmo quando o gestor manifestou disposição e capacidade de assumi-los. O debate em torno de novos cenários que concebem o SUS como uma rede-escola ${ }^{10}$ ainda não produziu mudanças consideráveis nas escolas médicas. Alegou-se, também, dificuldades para promover as adequações necessárias na rede básica para acolher estudantes, residentes e docentes. Há que se considerar, ainda, as disputas na universidade entre grupos que defendem diferentes modelos pedagógicos e de organização da assistência. A omissão do gestor neste caso, ao delegar ao próprio HE a responsabilidade de lidar com a situação a partir da sua correlação de forças internas, acabou protelando a mudança indicada na política. O estudo mostrou também que o gestor municipal, quando é médico e ligado ao HE, ao operar no âmbito da micropolítica, não fica imune ao jogo interno da organização hospitalar. Mesmo após as reformulações das diretrizes curriculares empreendidas pela Lei Federal que criou o Programa Mais Médicos e determinou que 30\% do internato fosse cumprido com ênfase na $\mathrm{AB}$, o HE continua como o centro formativo, mantendo em seu bojo diferentes ações de atenção primária ${ }^{11}$.

Parcela considerável da demanda básica continua acessando o HE por meio dos serviços de urgência, e os seus dirigentes, de maneira geral, alegam dificuldade em contra-referenciar os usuários pelas deficiências da rede básica. $\mathrm{O}$ modelo de cuidado centrado no médico e em procedimentos é reforçado no HE, e os usuários, protagonistas na construção dos seus mapas de cuidado, parecem não desejar substituir vínculos já estabelecidos e preferem ser tratados no $\mathrm{HE}^{12,13}$. A existência de usuários com doenças raras, acompanhados nos ambulatórios, é outro argumento utilizado para justificar cuidados básicos nos HE. Essas constatações reforçam estudo sobre as múltiplas lógicas de regulação do acesso à saúde, que evidenciou que usuários, em seu agir leigo, buscam entrar e se fixar ao HE, que passa a ser reconhecido como um ponto central e estável em seus mapas de cuidado ${ }^{14}$.
Baixo impacto foi observado na regulação da abertura de novos serviços nos HE que deveriam ser pactuados com o gestor do SUS, outra diretriz da política. Os gestores não assumem o ordenamento do sistema de saúde, não questionam os arranjos de poder e a autonomia dos médicos/ docentes, que continuam criando serviços à revelia da direção do HE e da universidade.

Essa questão merece duas considerações. A primeira diz respeito ao financiamento do governo federal para os HE. Quando são captados recursos através de emendas parlamentares, convênios ou outras iniciativas locais para expansão ou abertura de novos serviços, não se exige pactuação prévia com os gestores do SUS. Os dirigentes hospitalares reclamam que os gestores do SUS não remuneram os novos serviços prestados. $\mathrm{O}$ segundo aspecto diz respeito à própria organização e gestão do SUS no âmbito local, já que pouco se cogita qualificar a regulação, redefinir o perfil assistencial do HE, mudar o modo de produzir cuidado, monitorar e avaliar o uso dos recursos públicos implicados na relação de contratualização.

A política de contratualização não contribuiu efetivamente para a construção de redes integradas de cuidado, com a participação orgânica do HE no sistema de saúde, reorientando seu perfil assistencial e papel, como pretendia induzir. Foi possível, contudo, identificar avanços importantes na regulação do acesso e na utilização pelas centrais de regulação de leitos, consultas e procedimentos ambulatoriais ofertados pelos $\mathrm{HE}$ ao SUS, outra diretriz da política.

Entretanto, a diretriz que previa colocar a totalidade da oferta dos HE sob regulação do SUS efetivamente não se cumpriu, substituídos por mecanismo internos de regulação, como manutenção de cotas para ensino e pesquisa, indicando que, na maioria dos HE, o acesso ainda é fortemente definido e mediado pelos interesses da corporação médica/docentes.

Para agilizar a internação ou procedimentos utilizava-se a via judicial e a "urgencialização" do paciente eletivo, dispositivos microrregulatórios que se compõem com a lógica da regulação leiga, descrita por Cecílio et al. ${ }^{14}$, a partir das histórias de vida de usuários considerados grande utilizadores do sistema. No setor de urgência, médicos funcionam como chaves para o acesso a diferentes pontos do sistema. Eles e outros funcionários do HE utilizam sua rede de relacionamentos para pequenos favores, que extrapolam os controles normativos. Esse setor é ainda o lugar onde professores, residentes, alunos e pesquisadores escolhem casos com interesse acadêmico. 
A proposta de integração do HE ao sistema de saúde gerou resistências por parte dos médicos/docentes e era vista como traição à origem da instituição. Segundo o diretor clínico de um dos HE: "Estão vendendo o hospital para o SUS!". $\mathrm{Ou}$, no dizer de outro diretor clínico: "O gestor está retirando dos médicos e professores o poder sobre o hospital que lhes pertence!”.

A política teria que enfrentar o poder do docente/médico, mexer com a instituição médica, desorganizar os controles e espaços de poder instituídos até então. O HE, entretanto, tensionado pela demanda que escapa aos mecanismos regulatórios, e em virtude da complexidade das relações e interesses que se expressam no campo da micropolítica, resiste em ter sua oferta assistencial regulada pelos gestores do SUS. A concepção de contratualização adotada trabalha com forte dose de idealização de atores do SUS, em particular de gestores estaduais e municipais. Parte dos problemas cotidianos são resolvidos através de complexa rede de relações não-formais, operada fora dos contextos organizacionais tradicionais. Mas é possível afirmar que a agenda da regulação foi incorporada ao cotidiano dos $\mathrm{HE}$, reforçada pela política de contratualização, mesmo que com uma intensa e permanente disputa.

No que se refere às mudanças na qualidade da assistência prestada pelos $\mathrm{HE}$, avanços referentes à $\mathrm{PNH}$ estavam presentes em todos os $\mathrm{HE}$ estudados, embora vistos como algo anterior à contratualização. Para os entrevistados, a política fortaleceu e deu mais visibilidade à $\mathrm{PNH}$, mas não foi determinante.

Sistemas de classificação de riscos nos serviços de urgência, criação de ouvidorias, elaboração de protocolos assistenciais, guidelines, entre outras ferramentas voltadas à qualificação da assistência eram ações que também já vinham sendo adotadas, em sinergia com outras políticas governamentais, acompanhando tendências da gestão hospitalar que se intensificaram nos anos posteriores a coleta dos dados empíricos dessa investigação. A criação de comitês de ética, de prontuários, de investigação de óbitos, entre outros, apontados como evidências da qualificação da assistência, ou já estavam presentes ou foram induzidas pelo processo de certificação. A inexistência de processos de monitoramento, entretanto, impediu a avaliação sobre o real funcionamento e impacto sobre a qualificação da assistência ${ }^{15}$.

Não foi possível perceber consistentes mudanças almejadas no modelo de cuidado, a partir de linhas de cuidado, tema que ainda passava ao largo das discussões e pactuações no momento da contratualização.

\section{Gestão dos HE}

Os impactos mais significativos nos anos subsequentes à contratualização dos HE foram a ampliação do aporte de recursos e a mudança no modelo de financiamento. Ainda que percebidos de forma diferenciada por gestores e dirigentes dos $\mathrm{HE}$, e de forma mais positiva entre os dos HE federais, foram sempre destacados como mudanças mais visíveis e importantes da política, percepção corroborada por outro estudo ${ }^{16}$, que demonstrou que houve, entre 2003 e 2006, aumento do aporte financeiro dos HE federais contratualizados em $51 \%$, proporcionando o saneamento da grave crise, estabilidade e melhor capacidade de planejamento e gestão. De acordo com o superintendente de um HE estudado:

O novo método de financiamento melhorou muito a situação do hospital. [...] 100\% dos indicadores financeiros se inverteram. O crescimento do passivo passou a ter uma curva descendente. [...] a divida do hospital foi negociada. [...] A resposta objetiva e clara é que melhorou muito.

A despeito disso, aspectos problemáticos foram apontados pelos dirigentes. Em primeiro lugar, a inexistência de realinhamento periódico dos valores de incentivo à contratualização e a não incorporação de novos recursos para ampliação de serviços ao SUS para além do contratado, muitas vezes demandados pelo gestor. Além disso, a retenção, pelos gestores, de recursos disponibilizados para os HE pelo MS, a partir de mudanças no Fundo de Ações Estratégicas e Compensação (FAEC), incorporados aos procedimentos de média e alta complexidade. Em um HE estudado, administrado por OS, até os valores do incentivo à contratualização não foram repassados pelo gestor estadual, sob a alegação de que já mantinha um contrato global com o HE.

$\mathrm{O}$ aspecto mais crítico foi a manutenção da lógica de faturamento pela tabela do SUS, o que fez com que os HE relutassem em negociar mudanças no perfil de assistência e oferta de serviços, gerando restrição de oferta de urgência e de média complexidade, já que ampliar a alta complexidade resultaria em maior captação de recursos do SUS.

Outro aspecto foi a não implementação do financiamento global misto, com parte dos recursos fixos e parte recebida pelo cumprimento de metas contratualizadas, que deveriam aumentar, anual e progressivamente, até comporem 50\% do 
valor total a ser recebido pelo HE. O pagamento de alta complexidade seria mantido por produção, para não desestimular a oferta de serviços ao SUS. Alguns gestores locais “empacotaram" todos os recursos e fizeram o pagamento global fixo, sem fazer a gestão das metas contratualizadas. Houve, portanto, um desvirtuamento da lógica originalmente proposta.

Outro ponto de conflito diz respeito à disputa entre o MS e o MEC em relação ao custeio dos HE federais, tensionamento não resolvido e que resultou, entre outras coisas, na implantação da Empresa Brasileira de Serviços Hospitalares (EBSERH) e na mudança na normatização da política dos HE vinculados às instituições federais de ensino superior.

A política previa prazo de até quatro anos para que os HE públicos disponibilizassem 100\% de sua oferta para o SUS. Esse ponto, que tratava diretamente da relação público-privado, permanece não implementado.

$\mathrm{O}$ enfrentamento da crise financeira os HE abriu novas perspectivas, ampliando a governabilidade dos seus dirigentes, que passaram a utilizar o equilíbrio alcançado como dispositivo de validação dos projetos almejados. Para a implementação de ações definidas como estratégicas para o HE, seus dirigentes não hesitaram em inseri-las entre as metas do contrato e tensionar os demais atores internos ao HE a cumpri-las, apontando o risco de diminuição de recursos financeiros se não fossem implementadas, ainda que não fossem cobradas.

Ademais, pode-se apreender, a partir da empiria, que as metas escolhidas estavam sob governabilidade dos dirigentes e de cada setor do HE, sendo evitadas as que exigissem enfrentamento com a instituição acadêmica ou médica, interesses corporativos ou mudanças no processo de trabalho.

Os arranjos de participação e controle idealizados pela política, fortemente inspirados na produção de autores que enfatizam a necessidade de constituição de sujeitos coletivos, horizontalização e democratização das relações entre trabalhadores, usuários e gestores ${ }^{17}$, não conseguiram produzir uma nova lógica de gestão, mais visível e transparente.

A fragilidade dos mecanismos de acompanhamento e democratização da gestão, a ausência de iniciativas dos gestores locais para implementar o contrato, provocar mudanças, negociar e monitorar indicadores, metas e compromissos, constituíram-se em um dos pontos mais críticos da política de contratualização. As Comissões de
Acompanhamento dos Contratos, que deveriam envolver, além dos gestores, representantes dos usuários dos conselhos de saúde e da comunidade interna, ou não foram implementadas ou assumiram perfil marcadamente formalista, com caráter meramente homologatório e composição, por vezes, manipulada. O mesmo ocorreu em relação à instituição de Conselhos Gestores, que funcionaram protocolarmente, reproduzindo-se práticas identificadas em outras instâncias de participação social previstas no SUS ${ }^{18,19}$.

Prevaleceu entre os dirigentes dos HE a percepção de que os gestores do SUS apresentavam fragilidades técnicas na condução da política, e que o HE não era devidamente monitorado. De acordo com um dirigente entrevistado: "Estávamos muito mais preparados do que o que fomos cobrados. Tenho impressão que isso ia ajudar. A cobrança poderia ser mais rígida”.

Os gestores do SUS atribuíram um caráter secundário à gestão do contrato, já que se tratava de recursos oriundos da esfera federal. Deve-se considerar, todavia, que reconhecem que o HE é lugar de alta concentração de poder, e que dele dependem para garantir oferta de serviços em sua rede. Os dirigentes entrevistados consideram o HE um prestador complicado, de difícil controle.

Complacência é um conceito que caracteriza a postura dos gestores em relação ao acompanhamento das metas. Decorre da (não) capacitação do gestor e da fragilidade da estrutura pública responsável pela regulação, do quanto o HE é imprescindível para a assistência loco-regional, inviabilizando qualquer atitude mais radical de corte de recursos, e, de frequentes acordos de cavalheiros entre os atores que extravasam instâncias e procedimentos formais de controle propostos. Por um conjunto de razões locais, estabelece-se uma pauta de indulgência ${ }^{20}$ entre os atores que desacredita permanentemente os instrumentos de contratualização, fazendo com que percam sua potência. Esse talvez possa ser considerado um indicativo do quanto a lógica contratualista do processo de empresariamento do Estado ${ }^{21}$ pode não ter a potência de controle esperada, por estar eivada de um formalismo e de uma falsa transparência, que dificultam o efetivo acompanhamento, pelo Estado, do desempenho dos entes contratados.

Destaque-se, igualmente, que o governo federal não cumpriu sua parte. Apesar do montante de recursos implicados na política e o conjunto de apostas envolvidas, os gestores federais entrevistados reconheceram que não conseguiram 
implementar mecanismos de monitoramento da política. A única estratégia efetiva foi a certificação, para enquadramento no conjunto de normativas da política, mas que não se colocou objetivamente em confronto com as questões de fundo que colonizam o $\mathrm{HE}$, em particular as que estão no âmbito da instituição acadêmica e da instituição médica. Assim, o formal e precário funcionamento das comissões de avaliação dos contratos não foi um achado isolado e é um importante elemento avaliativo. As dificuldades na contratualização dos HE continuam presentes, ainda que poucos avanços, para além da relação contratual formal, tenham sido produzidos ${ }^{15,22}$.

Um dos problemas mais importantes observados foi a não capilarização das metas para dentro do hospital. O conhecimento dos termos contratualizados entre os trabalhadores era baixíssimo. A contratualização não produziu também a horizontalização da gestão e planejamento participativo dos HE. A maioria dos HE contava com planos diretores, mas não foram elaborados com participação dos trabalhadores ou, ao menos, das gerências intermediárias. Se houve algum impacto na qualificação do planejamento, foi atribuído a processos de acreditação em curso, inseridos no movimento mais amplo de reestruturação gerencial instituído em todo o país ${ }^{23,24}$.

Um dos aspectos mais relevantes da contratualização foi a intensa utilização da informação como instrumento gerencial que, por vezes, assumia um caráter de fetiche. Em todas as esferas de governo e no interior dos HE estudados, reinava certa expectativa de que a adoção de um sistema de informações eficiente seria capaz de ampliar o controle sobre a complexa vida do HE, dandolhe a visibilidade e previsibilidade necessárias.

A informatização emergiu como a base tecnológica principal da nova racionalidade organizacional desejada, mas, paradoxalmente, marcada por fortes elementos de irracionalidade, entre os quais a existência de múltiplos sistemas em uso, desarticulados entre si ou redundantes, deixando transparecer o irracional dentro do racional. De um lado, os dirigentes dos $\mathrm{HE}$, reagindo com desconforto aos sistemas distintos, alimentados para cumprir formalidades exigidas pelos gestores que, por sua vez, acreditavam que qualificariam o monitoramento com novas ferramentas informatizadas.

Instrumentos de gestão pensados como potentes, per se, para induzirem transformações na vida organizacional, tornam-se simulacros ou meras formalidades quando implementados, sem produzir novas configurações das relações de poder na vida hospitalar. A contratualização envolve vários atores que disputam seus projetos em ato na micropolítica dos $\mathrm{HE}$, mas se, de algum modo permitiu fortalecer a alta direção, não foi capaz de propiciar a inclusão de novos atores e transformar substantivamente a dinâmica organizacional. Isso não se deu por falta de capacitação, de instrumentos gerenciais ou "tempo de maturação" da política, como propugna a concepção funcionalista prevalente, mas pelas limitações de concepção e formulação da própria política de contratualização dos HE.

Dirigentes dos HE e gestores federais atribuíram peso significativo à falta de capacitação dos gestores locais do SUS para explicar deficiências e fracassos da política de contratualização. Preconizaram, como medida corretiva, mais cursos de capacitação de gestores, que assumem também caráter de fetiche, à semelhança dos sistemas de informação.

\section{Formação e EP}

O impacto dessa diretriz foi pouco significativo. Mudanças na formação em saúde que utilizam novos cenários de ensino fora do ambiente hospitalar foram tratadas como iniciativas isoladas. Todavia, significativas melhorias em infraestrutura de ensino nos HE (espaços para aulas e reuniões, laboratórios, bibliotecas e o acesso à internet) foram ressaltadas, atribuídas à indução desencadeada pela certificação, pois eram quesitos observáveis na qualificação do estabelecimento como HE.

A participação dos HE na formação de profissionais do SUS foi inexpressiva. Para os dirigentes dos HE, os gestores não demandaram processos de capacitação e EP, e as ofertas em cursos e outras atividades não tiveram adesão dos profissionais da rede. As metas apresentadas nesse eixo não foram cumpridas e os HE só não foram penalizados porque as Comissões de Acompanhamento dos Contratos funcionavam apenas formalmente. Os gestores alegaram que os $\mathrm{HE}$ estão distantes das necessidades do SUS, mas não utilizaram o contrato de metas para apresentar suas demandas. Na prática, a relação com o HE mantém-se restrita à dimensão assistencial. É difícil identificar até que ponto esse quadro pode ser explicado pelo desinteresse ou fragilidade dos gestores do SUS ou pelo tipo de proposta de formação e EP que o HE pode proporcionar.

Outro aspecto relevante diz respeito ao investimento na educação continuada nos $\mathrm{HE}$. A receita preconizada para os problemas era a 
capacitação em massa dos empregados e a formação de gestores hospitalares para aplicar as técnicas e ferramentas de gestão. Poderosos sistemas de informação e forte investimento em capacitação gerencial acabaram sendo realizados, de forma bastante simplificada, com expectativa de se constituírem em estratégias para enfrentar a complexa trama das relações que atravessam e constituem a vida organizacional.

Observou-se, ainda, que há confusão conceitual em relação a capacitação, educação continuada e EP, tratadas como sinônimos. A EP prevê processos de longo prazo, com forte participação e protagonismo dos gestores e/ou trabalhadores, a partir de seus problemas cotidianos, com a pretensão de ir além dos processos formais de capacitação ligados à educação continuada, com enfoques mais pontuais e menos potência para transformar práticas ${ }^{10,25}$. O discurso contido na proposta de EP, concebida pelo MS, orientavase por um sentido ético-político-emancipatório bem definido, mas acabou sendo traduzido no cotidiano dos HE e da gestão local como educação continuada, com ênfase em capacitações. Mais um elemento que aponta para a distância entre discurso e a prática.

\section{Produção de conhecimentos e incorporação tecnológica a partir das necessidades do SUS}

Há uma percepção generalizada de que a política não teve potência suficiente para disparar mudanças nesse eixo. Os gestores do SUS não introduziram em suas agendas esses temas. Mesmo estabelecimentos de ensino apontados pelos dirigentes federais como experiências referenciais na implementação da política apresentaram resultados reconhecidamente inexpressivos.

As tímidas mudanças observadas, restritas à implantação de Comissões de Ética, de Estudos e Pesquisas e de diretorias de pesquisa, indicam que a certificação teve, também nesse eixo, caráter indutor mais marcante do que a contratualização. Ademais, serviram como tentativas da alta direção dos HE em disciplinar e controlar a situação caótica vigente. A regulação de leitos pelo gestor e a criação das diretorias de ensino e pesquisa nos HE permitiu a introdução de movimentos regulatórios da produção de pesquisas nas instituições, alterando o padrão anterior, marcadamente ditado por interesses acadêmicos. Cabe avaliar se seriam dispositivos internos à micropolítica com poder de condução de novas posturas, constituindo-se num caminho mais micropolítico a ser seguido.
Vale destacar os principais limites do recorte metodológico adotado para o estudo. Não foi possível apreender a avaliação de outros atores organizacionais que atuam em posição estratégica no HE e, através deles, captar possíveis ressonâncias da almejada capilarização da política na vida organizacional. Não foi possível tecer considerações comparativas entra a gestão estadual e municipal dos HE, ainda que não apontem diferenças substantivas. Não foi possível, ainda, consideraras mudanças ocorridas nos últimos anos na gestão dos HE federais a partir da criação da EBSERH. Um HE federal selecionado ainda não aderiu à EBSERH e o outro só estabeleceu seu primeiro contrato em maio de 2018. Por fim, deve-se considerar, ainda, a descontinuidade - ainda que não formal - na condução das políticas a partir das profundas mudanças ocorridas no cenário político brasileiro, a partir de 2016, que afetaram diversas políticas públicas conduzidas pelo MS e o MEC. Se não revogadas, tiveram ritmos de implementação comprometidas ou tomaram outros rumos. Isso, de certa forma, amplia a importância de analisar uma política empreendida num momento histórico ímpar.

\section{Considerações finais}

A política de contratualização dos HE trouxe benefícios concretos. Sua face mais visível, no período estudado, foi o equilíbrio econômicofinanceiro e diminuição do endividamento. Permitiu, ainda, um saldo organizativo e melhorias na regulação do acesso dos usuários do SUS em todos os $\mathrm{HE}$ estudados. Outros avanços parecem ser mais decorrentes das intervenções prévias, exigidas para a certificação como HE, ou resultantes do sinergismo com outras políticas governamentais em curso, resultados que apresentam marcadas convergências com outra investigação ${ }^{26}$. Ensino, EP, pesquisa e incorporação tecnológica foram finalidades negligenciadas. A gestão do cuidado e os processos mais micropolíticos da organização do trabalho das equipes não foram enfrentados.

A política forjou um projeto consistente, idealizado, repleto de princípios e intenções louváveis, mas que terminou por reproduzir o comportamento conservador que caracteriza a gestão pública, uma racionalidade instrumental que dá ênfase ao ato administrativo e à normatização excessiva. Foi elaborada a partir de uma concepção de gestão com viés estrutural-funcionalista, com forte ênfase na padronização de processos, 
aumento da visibilidade e responsabilidade de todos os setores (e atores) do hospital, na busca incessante pela previsibilidade e regularidade, e uma crescente capacidade de controle, através do uso intensivo e cada vez mais sofisticado da informática.

O material empírico apresenta diversas pistas de que a política acabou se constituindo em um jogo dos atores ausentes; isto é, o quanto os projetos formulados pelo Movimento Sanitário, mesmo quando generosos e arrojados, concebem atores idealizados que nunca atuam como o esperado. Pressupunha a adesão de atores capazes de operacionalizar a política que não existiam na potência desejada ou cujo desempenho não foi compatível com as responsabilidades atribuídas. Não existe o gestor público do SUS idealmente qualificado. A direção hospitalar, em geral, é ainda muito fragilizada. A contratualização se deu em um campo produzido pelas relações de forças locais que também deformam os vetores racionalizantes propostos pela política. O HE é campo de grandes disputas, embora não necessariamente ruidosas, da instituição acadêmica e da instituição médica.

Os achados empíricos do estudo provocam um deslocamento de olhar de exterioridade que caracterizou a formulação inicial do estudo para o interior da própria política. A expectativa de que uma nova racionalidade gerencial seria capaz de superar conflitos e disputas a partir de uma política governamental, sem considerar a complexidade da micropolítica do $\mathrm{HE}$, não se concretizou. O conjunto de dispositivos propostos, quando muito, foi apropriado por algumas direções dos hospitais para ampliar, consolidar ou simplesmente legitimar projetos de mudança em curso.

Fundamentada num projeto ético-político que almeja construir o novo HE (democratizado, transparente em todas as dimensões de sua gestão e compromissado com a construção do SUS enquanto política pública), a política de reestruturação dos HE acabou sendo implementada com elementos afeitos ao referencial estruturalfuncionalista, reproduzindo os instituídos que se propunha transformar. A teoria - especificamente os conceitos e o modo de pensar o mundo tem profunda influência no nosso modo de agir e de pensar a gestão. Há elementos conceituais -operatórios da política que exigem revisão.

Poderia ser dito que a política teve o grande mérito de apontar um novo modo de relacionamento entre o SUS e os HE, o que não é pouca coisa se considerados o isolamento e o descompromisso vigente, bem como seu atravessamento por inúmeros interesses privados, da cátedra ao complexo médico-industrial.

A política da contratualização, nesse sentido, representa um marco na política de saúde no nosso país, fato reconhecido por quase todos os entrevistados. No entanto, o material empírico é cheio de indicações sobre como as diretrizes e princípios mais ambiciosos e generosos da política ainda apenas tocaram a superfície desse desafiador território que é o $\mathrm{HE}$, de modo que o estudo indica a importância da revisão crítica do seu ponto de partida teórico-conceitual, esperando contribuir, assim, para futuras intervenções e estudos.

\section{Colaboradores}

A Chioro e LCO Cecílio trabalharam na concepção, delineamento, metodologia e redação do artigo. A Chioro e R Andreazza trabalharam na revisão final da versão publicada. LAC Furtado, EC Araújo e MA Nasser trabalharam na revisão crítica e aprovação da versão publicada.

\section{Financiamento}

Fundação de Amparo à Pesquisa de São Paulo (Fapesp). 


\section{Referências}

1. Reis AAC, Cecílio LCO. A política de reestruturação dos hospitais de ensino: notas preliminares sobre os seus impactos na micropolítica da organização hospitalar. Saude Debate 2009; 33(81):88-97.

2. Brasil. Portaria Interministerial $n^{\circ}$ 562/MS-MEC-MCT-MPOG, de 12 de maio de 2003. Constitui a Comissão Interinstitucional com o objetivo de avaliar e diagnosticar a atual situação dos Hospitais Universitários e de Ensino no Brasil, visando reorientar e/ ou reformular a política nacional para o setor. Diário Oficial da União; 2003.

3. Brasil. Ministério da Saúde (MS). Reforma do Sistema de Atenção Hospitalar Brasileira. Cadernos de Atenção Especializada n. 3. Brasília: MS; 2004.

4. Brasil. Ministério da Saúde (MS). Coordenação Geral de Atenção Hospitalar/DAE-SAS. Nota Técnica 43: Política de Reestruturação dos Hospitais de Ensino: processo de certificação e contratualização. Brasília: MS; 2006.

5. Brasil. Ministério da Saúde (MS). Secretaria Executiva. Humiza SUS: política nacional de humanização. Brasília: MS; 2003.

6. Brasil. Ministério da Saúde (MS). Portaria GM no 2.048 , de 5 de novembro de 2002. Institui o Regulamento Técnico dos Sistemas Estaduais de. Urgência e Emergência. Diário Oficial da União; 2002.

7. Reis AAC, Sóter APM, Furtado LAC, Silva SS Pereira. Reflexões para a construção de uma regionalização viva. Cien Saude Colet 2017; 22(4):1045-1054.

8. Cecilio LCO. A micropolítica do hospital: um itinerário ético-político de intervenções e estudo [tese]. São Paulo: Unifesp; 2007.

9. Marins JJN, Rego S, Lampert JB, Araújo JGC, organizadores. Educação Médica em Transformação: instrumentos para a construção de novas realidades. São Paulo: Hucitec-Abem; 2004.

10. Ceccin RB, Feurwerker L. O quadrilátero da formação para a área da saúde: ensino, gestão, atenção e controle social. Physis 2004; 14(1):41-65.

11. Pinto HA, Andreazza R, Ribeiro RJ, Loula MR, Reis AAC. The More Doctors Program and the changing role of the State in the regulation and organization of medical education. Interface (Botucatu) 2019; 23(Supl. 1):e170960.

12. Demétrio F, Santana ER, Pereira-Santos M. O Itinerário Terapêutico no Brasil: revisão sistemática e metassíntese a partir das concepções negativa e positiva de saúde. Saude Debate 2019; 43(n. esp. 7):204-221.

13. Cecilio LCO, Carapinheiro G, Andreazza R, organizadores. A regulação como produção social: os múltiplos regimes de regulação. In: Os mapas do cuidado: $o$ agir leigo em saúde. São Paulo: Hucitec; 2014.

14. LCO, Carapinheiro G, Andreazza R, Souza ALM, Andrade MGG, Santiago SM, Meneses CS, Reis DO, Araújo EC, Pinto NRS, Spedo SM. O agir leigo e o cuidado em saúde: a produção de mapas de cuidado. Cad Saude Publica 2014; 30(7):1502-1514.
15. Lira GV, Nogueira DL. Teoria e Método para um Modelo de Avaliação dos Hospitais de Ensino no Brasil. Rev Bras Educ Med 2016; 40(1):4-10.

16. Lobo MSC, Silva ACM, Lins MPE, Fiszman R. Impacto da reforma de financiamento de hospitais de ensino no Brasil. Rev Saude Publica 2009; 43(3):437-445.

17. Cecilio LCO. Inventado a mudança na saúde. São Paulo: Hucitec; 1994.

18. Santos TBA, Pinto ICM. Política Nacional de Atenção Hospitalar: con(di)vergências entre normas, Conferências e estratégias do Executivo Federal. Saude Debate 2017; 41(n. esp. 3):99-113.

19. Kezh NHP, Bógus CM, Martins CL. Entraves à participação social dos representantes dos trabalhadores no conselho municipal de saúde. Saude Soc 2016; 25(4):950-963.

20. Silverman D. Teoria de lasorganizaciones. Buenos Aires: Editora Nueva Visón; 1975.

21. Gruening G. Origin and theoretical basis of new public management. Int Public Management J 2001; 4:125.

22. Santos TBA, Souza JS, Martins JS, Rosado LB, Pinto ICM. Gestão indireta na atenção hospitalar: análise da contratualização por publicização para rede própria do SUS. Saude Debate 2018; 42(n. esp. 2):247-261.

23. World Health Organization (WHO). The International Journal of Public Health, Special theme: contracting and health services. Bull WHO 2006; 84:11.

24. Forgia GM, Couttolenc BF. Desempenho Hospitalar no Brasil. Em Busca da Excelência. São Paulo: Editora Singular, The World Bank/ IBEDESS; 2009.

25. Ceccin RB. Educação permanente em saúde: descentralização e disseminação de capacidade pedagógica na saúde. Cien Saude Colet 2005; 10(4):975-986.

26. Lima SML. Possibilidades e limites da contratualização para o aprimoramento da gestão e da assistência hospitalar: o caso dos hospitais de ensino do SUS brasileiro [tese]. Rio de Janeiro: Fiocruz/ENSP; 2009.

Artigo apresentado em 13/03/2020

Aprovado em 03/09/2020

Versão final apresentada em 05/09/2020

Editores-chefes: Romeu Gomes, Antônio Augusto Moura da Silva 